\title{
A INDÚSTRIA CARBONIFERA RIO-GRANDENSE E A QUESTÃO ENERGÉTICA
}

\author{
Sandra Jatahy Pesavento
}

\section{1 - DOS PRIMÓRDIOS A DÉCADA DE 20}

A exploração do carvão no sul do país está relacionada com o próprio desenvolvimento do capitalismo em sua expansão. Particularmente, a questão energética assumiu relevância com a emergência da chamada Revolução industrial, marcada pelo surgimento da fábrica e pela expansão das ferrovias, ambos vinculados à invenção da máquina a vapor.

Segunda forma histórica de produção capitalista, a fábrica distingue-se da fase manufatureira que a precedeu pela introdução da máquina no processo produtivo, oportunizando a real subsunção do trabalho ao capital e o aumento da produtividade.

A Inglaterra, que já vinha liderando o processo de transformação capitalista na fase manufatureira, manteve a sua posição pioneira no contexto das transformações tecnológicas que se realizaram. Incrementaram-se no território inglês, desde a segunda metade do século XVIII, as atividades de exploração das minas de carvão que atendiam as necessidades crescentes das fábricas, estradas de ferro e companhia de navegação a vapor. Dentro de uma divisão internacional do trabalho, as naçōes centrais, lideradas pela Inglaterra, exportavam produtos manufaturados para as nações periféricas, fornecedoras de matérias-primas e gêneros agrícolas tropicais necessários ao desenvolvimento capitalista mundial.

Entretanto, no decorrer do século XIX, verificou-se o processo de expansão do capital a nível mundial, processo este que, desde a ótica dos países periféricos, implicou a internalização do modo de produção capitalista.

O capital passou a apoderar-se da produção naquelas áreas do globo que já se vinculavam ao mercado mundial de forma capitalista, mas onde, internamente, o processo de trabalho não se realizava em moldes capitalista. No caso brasi- 
leiro, este momento foi assinalado pela passagem da forçatrabalho escrava para a força-trabalho livre.

$\mathrm{Na}$ sua posição de nação pioneira e já vinculada ao Brasil por laços de dominação-subordinação já há mais de um século, a Inglaterra passou a exportar capitais e a operar no setor de serviços públicos. Proliferaram os empréstimos e os bancos ingleses, bem como passaram a operar no pais as ferrovias, os navios e as companhias de iluminação a gás britânicas. Dentro deste contexto, começou a assumir relevância a importação do carvão inglês, que se destinava a dinamizar esta rede de serviços que se expandia, bem como abastecer as poucas empresas que utilizavam a máquina a vapor.

Inserido neste processo, o Brasil passou a oferecer um novo setor para o investimento do capital inglês: as minas de carvão, que viriam a se constituir numa fonte alternativa de fornecimento de energia para as fábricas britânicas.

Assim, a descoberta e a exploração das jazidas carboniferas se tornaram alvo das preocupaçōes do capitalismo inglês e dos governos locais.

O interesse do governo, no caso, orientava-se para a possibilidade de encontrar, em solo brasileiro, jazidas que permitissem o seu aproveitamento em substituição a similar importado.

Entretanto, faltava ao Brasil a tecnologia necessária à prospecção, bem como o capital suficiente para manter a exploração.

Para ambos os casos, os governos recorreram ao capital inglês. Embora a descoberta das minas, se efetivada, redundasse na diminuição da importação do carvão britânico, a Inglaterra seria também beneficiada com isso, pois as empresas e companhias inglesas que aqui operassem poderiam utilizar-se de combustivel local, além de realizar a sua exportação para a própria Grã-Bretanha, caso as jazidas fossem consideráveis.

No caso do Rio Grande do Sul, as primeiras descobertas de carvão datam de 1809, nos arredores de Rio Pardo, tendo sido feitas por Eschewege, técnico contratado especialmente para este fim por capitais particulares ingleses. 
As "Memórias econômico-políticas", de Gonçalves Chaves, escritas em 1821, dão notícia da existência deste carvão de pedra em território rio-grandense.

Segundo Chaves, tais jazidas se deveriam explorar " (...) a proporção e a grandeza de nossas cidades do interior, aperfeiçoamento da navegação de nossos caudalosos rios e fábricas de pálvoras e outras proporcionem o consumo"1.

Somente em 1840 começaram as explorações em caráter oficial, tendo o governo provincial contratado os serviços do mineiro inglês James Johnson. Em 1853, este descobriu uma bacia carbonifera no vale do Arroio dos Ratos, em São Jerônimo. Conforme o relatório do inglês, o carvão parecia ser de boa qualidade, tal como o importado que era consumido no uso dos vapores, gás e ferrovias².

Foi através do capital inglês que se iniciou a exploração das jazidas no Rio Grande do Sul. Pelo Decreto no 2.819, de 21 de agosto de 1861, foi concedido ao mineiro britânico Johnson um privilégio por dois anos para explorar as minas de Arroio dos Ratos, privilégio este ampliado para 30 anos pelo Decreto $n$ ? 3.715, de 6 de outubro de 1867, quando a empresa já contava com os sócios Inácio José Ferreira de Moura e outros ingleses, como MacGinity.

A presença de capitais britânicos no negócio motivou a uma nova ampliação da empresa. Em Londres, Johnson levantou um capital de $100.000 £$, e o governo provincial gaúcho, por seu lado, tomou $10.000 £$ em ações. Como resultado desta ampliação toda, foi formada em 1872 a Imperial Brazilian Collieries Co. Ltd3.

A companhia começou a construção de uma estrada de ferro entre as minas e o porto de São Jerônimo, às margens do Jacui, e Johnson comprometeu-se a embarcar o carvão neste ponto a 7 shillings a tonelada, o qual a companhia venderia em Porto Alegre a 25 shillings, enquanto que o carvão inglês custava 60 shillings 4 .

Note-se, no caso, o entrelaçamento dos interesses ingleses quanto ao carvão e às estradas de ferro. John MacGinity, sócio de Johnson, foi um dos pioneiros da estrada de ferro de Novo Hamburgo a Porto Alegre, além de ser representante na província de várias firmas inglesas e companhias de seguros. 
Constatando esta realidade, afirmava Mulhall ao visitar a província nos inícios da década de 70 do século passado:

"Estradas de ferro, dragagem, obras de gás, minas de carvão, fundições, etc., estão na ordem do dia. Todos os novos empreendimentos estão nas mãos de engenheiros ingleses e - capital necessário, na maioria dos casos, é também conseguido na Inglaterra" 5 .

Em 1878, com a morte de Johnson, a companhia inglesa encerrou as suas atividades neste ramo sendo vendido o negócio à casa Holtzweissig \& Cia., de Porto Alegre. A casa Holtzweissig vinha operando, até então, como uma companhia imigratória, responsável pela entrada de colonos alemães na província.

Sob a direção de Holtzweissig, constituiu-se a companhia "Minas de Carvão de Pedra de Arroio dos Ratos". Em 1881, já compareciam à Exposição Brasileiro-Alemã de 1881 com amostras de carvão.

O governo provincial depositava esperança nos fornecimentos que a empresa faria aos navios da armada, mas indicava que só a presença do capital europeu possibilitaria meIhorias no setor6.

$\mathrm{Na}$ realidade, o capital investido revelou-se insuficiente, e a companhia faliu em 1888, sem conseguir manter uma exploração regular. A falência ocorreu justamente no momento em que se tentava um entendimento entre ela e a Cia. Rio-grandense de lluminação a Gás, a fim de ser realizada uma experiência com o carvão nacional para a iluminação de Porto Alegre 7 , bem como se tentavam fazer experiências para verificar se o mesmo se prestava para a fabricação de hidrogênio8.

Paralelamente às explorações realizadas na mal sucedida mina de Arroio dos Ratos, processavam-se, no estado prospecções na zona de Candiota. Os ingleses Nataniel Plant e John Anderson eram os concessionários da exploração, para o que mantiveram contatos com casas bancárias estrangeiras, mas o carvão extraído foi considerado de qualidade inferior ao da jazida de Arroio dos Ratos. Já em 1882, haviam sido realizados alguns estudos na serra de Butiá, petro de São Jerônimo, tendo os resultados revelado a presença de carvão de qualidade semelhane ao do Arroio dos Ratos. 
Com o advento da República, foi formada no Rio de Janeiro, com capitais nacionais, a "Cia. de Estrada de Ferro e Minas de São Jerônimo", para prosseguir na exploração das jazidas de Arroio dos Ratos.

Nota-se portanto que, ante as dificuldades que se apresentaram para a extração do carvão, o capital estrangeiro desistiu do empreendimento, demandando áreas mais lucraticas de investimento. Por outro lado, face a escassez dos recursos da província, foram os capitais vinculados ao núcleo central da economia - o centro cafeicultor formado pelo eixo São PauloRio - os que se dispuseram a investir no sul.

Com a criação da nova companhia, foram perfurados quatro poços para os trabalhos das minas, mas a produção do minério atendia mais ao consumo de algumas indústrias existentes, "não se generalizando o seu uso na Viação Férrea e na navegação fluvial e marítima" 9 .

Salvo no período da Revolução Federalista, quando o carvão foi regularmente aproveitado pela estrada de ferro de Porto Alegre a Uruguaiana, seu consumo não se generalizava, tal como haviam desejado os capitais ingleses e o governo.

Continuava em grande escala a importação do carvão de pedra estrangeiro que, em 1902, aparecia como o sexto produto na pauta das importações do estado, com um valor de Cr\$ 575:594\$00010.

Praticamente, o carvão rio-grandense utilizado como combustivel equivalia à metade do combustivel estrangeiro consumido no estado.

$\mathrm{Na}$ medida que a produção interna não era suficiente para abastecer as necessidades da demanda local, a importação do carvão inglês vinha revelar um outro problema para a indústria carbonifera gaúcha: o produto estrangeiro era de melhor qualidade e mais barato.

Quanto à qualidade do produto, o carvão nacional continha muitas impurezas, tais como o enxofre. Neste sentido, surgiam em 1905 auspiciosas notícias de que, segundo experiências realizadas nos Estados Unidos, o carvão rio-grandense poderia ter utilização industrial compatível, do ponto de vista técnico, com o similar estrangeiro, desde que submetido a condições especiais de preparo físico e adequação de aparelhos. 
"(...) quando queimados em motores gás, que, não exigindo custo de instalação superior ao dos motores a vapor com as caldeiras e conservando-se com inferior dispêndio do que estes, começarão a ser preferidos"'11.

Entretanto, embora a notícia fosse considerada como a "nova aurora" do carvão nacional, na prática não se efetivava o seu aproveitamento generalizado naquele sentido.

Quanto ao preço do carvão Cardiff ser inferior ao do nacional, deve ser levado em conta o alto custo operacional da prospecção e exploração das jazidas no sul do pais frente a exigüidade do capital nacional aplicado na "Cia. Estradas de Ferro e Minas de São Jerônimo". Sendo alto o custo da produção do carvão, o preço de mercado dos mesmos também se colocava elevado.

Face a tais problemas, não se apresentava como alternativa para o combustível apenas o carvão Cardiff, mas também a lenha, de mais baixo custo e, portanto, sendo usada preferencialmente na viação férrea e fluvial e nos estabelecimentos industriais 12 .

A questão energética passou a preocupar os governos republicanos, federal e estadual.

O presidente Rodrigues Alves iniciou seu mandato com um programa de reerguimento econômico do país que incluia a realização de obras públicas, como o arruamento e a urbanização da capital federal, assim como a construção e o apareIhamento de portos e estradas de ferro. "O governo já se preocupava com o consumo do combustivel, voltando os olhos para as jazidas carboniferas do sul e para a possibilidade de seu transporte através do Rio Grande. O consumo de combustível procedente da Inglaterra nas estradas de ferro fazia com que as despesas de custeio ombreassem com a receita total."'13

Neste ponto, confluíam os interesses dos governos federal e estadual. Desde o ponto de vista do centro, tornava-se necessário acelerar os trabalhos de conclusão da abertura da barra e da construção do porto do Rìo Grande, bem como intensificar a exploração das minas de carvão gaúchas, a fim de melhor abastecer as vias férreas da zona cafeeira de um combustivel fornecido a mais baixo preço que o carvão inglês. 
Segundo o presidente do estado Borges de Medeiros, a solução da "questão dos transportes" era o principal problema a ser resolvido pelo governo. Desde 1903 que o governante gaúcho propusera ao governo federal que fossem transferidos para a esfera estadual os serviços de abertura da barra e construção do porto do Rio Grande, que se achavam operando, de forma ineficaz, sob o regime de concessionária estrangeira.

A União já possibilitara a introdução no país, sem pagamento de impostos de importação, das máquinas e outros instrumentos necessários à mineração14, bem como contratara os serviços do engenheiro americano J. C. White para estudar a existência de jazidas carboníferas desde as minas de Tubarão, em Santa Catarina, até o Rio Grande do Sul.

No relatório apresentado em 1906 ao ministro da Viação sobre o resultado de suas investigações e experimentações do carvão gaúcho em locomotivas da Central do Brasil, o engenheiro White concluiu pela necessidade de adaptação das grethas para facilitar a combustão e retiradas das cinzas 15 .

Em suma, a utilização plena do produto gaúcho demandava aperfeiçoamentos técnicos, o que, por sua vez, exigia mais capital.

Quanto ao governo estadual, este assim se referia ao pro. blema na mensagem enviada à Assembléia de Representantes em 1904:

"De nossa parte, isentando de quaisquer taxas esse combustivel (carvão) e diminuindo o consumo de lenha nos transportes fluviais e terrestres, teremos instituído um regime de franca proteção, que precisará, apenas, como complemento, a criação de taxas mais elevadas sobre a introdução do carvão estrangeiro"16.

Um fator, contudo, iria aumentar as atençöes do governo para com a exploração do carvão e mesmo possibilitar a sua expansão no estado.

A eclosão da Primeira Guerra Mundial veio determinar uma perturbação no comércio internacional. A escassez dos transportes marítimos, aliada à elevação geral dos preços, veio tornar proibitivo o fornecimento regular e a aquisição do carvão estrangeiro. 
Mesmo com a elevação do preço do carvão rio-grandense - atingiu $50 \$ 000$ a tonelada, quando a expectativa era de $33 \$ 000$ para poder cobrir as despesas de custeio e juros de capital - o seu consumo ampliou-se no estado e fora dele.

Por exemplo, em 1915, a mina de gás de Pelotas viu-sə "desfalcada de suas reservas de carvão, voltando-se para 0 carvão do Arroio dos Ratos"17.

Face a esta situação, o governo do estado preocupou-se em amparar de forma mais decisiva, a indústria carbonífera e incentivar a sua exploração.

Em 1915, "concedeu a Otto Spalding e Otto Kar Pauthner, um auxilio de 25 contos de réis para a exploração das minas da Porteirinha, no município de São Jerônimo, obrigando-se os mesmos a restituir, em combustivel, o numerário recebido"18.

Neste mesmo ano, formava-se em Porto Alegre a Cia. Hulha Rio-grandense, com capitais particulares, para explorar as jazidas de carvão de Minas de Butiá, em São Jerônimo. Reorganizada com o capital de 1.000:000\$, no Rio de Janeiro, esta companhia foi incorporada à "Cia. Minas de Carvão do Jacui", sob a denominação de "Cia. Carbonífera Rio-grandense". Recebeu um auxílio do governo federal na ordem de 1.800:000\$000 e a construção de um ramal ferroviário para transportar o minério até o porto fluvial. Organizada definitivamente em 2 de maio de 1917, a Cia. Minas de Carvão do Jacui já contava com um capital de 3.000:000\$000 para operar com serviços de exploração de carvão, estrada de ferro e navegação19.

Desta forma, a empresa contou, para a sua constituição, com recursos de particulares e do governo federal, que teria o seu capital restituído em fornecimentos de carvão para o Lloyd Brasileiro.

O minério era extraido das jazidas existentes em São Jerônimo, na Fazenda do Leão, a qual a companhia arrendara pelo prazo de 60 anos com o compromisso de pagar $1 \$ 000$ por tonelada de carvão extraído. Considerando que, em 1917, a tonelada de carvão atingia $70 \$ 000$, as perspectivas de lucro eram boas. Paralelamente às explorações das minas de Butiá e Leão, a "Cia. de Estrada de Ferro e Minas de São Jerônimo" continuava a exploração de suas jazidas, com um capital de $5.000: 000 \$ 000$. 
Em 1917, sua produção mensal era de 10.500 toneladas, das quais 8.350 eram vendidas para as seguintes empresas 20 :

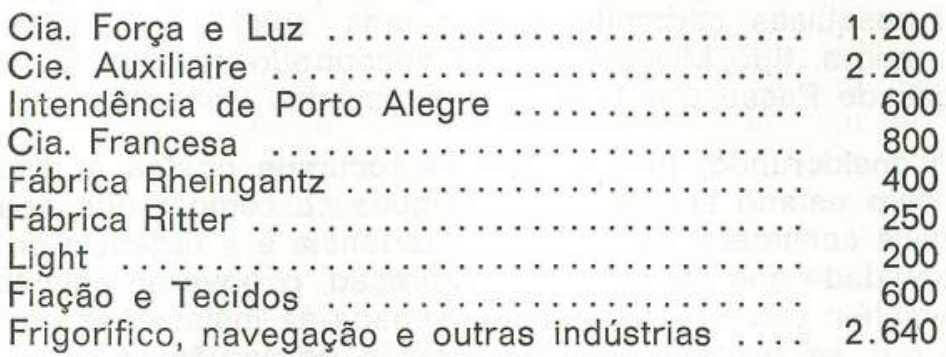

Em 1918, ampliou sua produção para 18.000 toneladas mensais, fornecendo também carvão para a Secretaria de Obras Públicas, Intendências de Pelotas e Rio Grande, Lloyd Brasileiro, Cia. Costeira e Estrada de Ferro Central do Brasil21.

A companhia se achava abrindo novos poços, adquirindo novos materiais e ampliando as ligações ferroviárias, além de adquirir novos terrenos carboniferos.

Frente a conjuntura favorável propiciada pela guerra, o auxílio dos poderes federais e o interesse dos capitais particulares, o governo estadual apresentava à Assembléia de Representantes as seguintes conclusões:

"1 que antes da guerra era nulo o consumo do carvão nacional por sua inferioridade relativa e custo elevado, sendo absolutamente preferido o carvão estrangeiro;

2 que até então precária era a situação da única companhia exploradora de carvão, a de Arroio dos Ratos, cuja produção diminuta e incerta mal cobria as despesas;

3 que o capital bancário mostra-se refratário à indústria carbonifera, que por essa razão não tem tomado impulso;

4 que nehnuma iniciativa ou nova empresa tem logrado vingar sem o auxílio ou garantia oficial da União, do que é exemplo frisante a Cia. Minas do Jacuí, para cuja formação contribuiu o governo federal com a metade do capital social além de outros favores relevantes"22.

O governo estadual já havia, pela Lei no 14 , de 1 i de dezembro de 1916, concedido auxílios até 500:000\$ para todas as 
empresas que se destinassem à exploração do carvão no Rio Grande. Além disso, em julho de 1917, fora criada a Diretoria do Serviço Geológico e Mineralógico, que começara em Gravatai pesquisas carboniferas com uma sonda de percussão, perfuradora, tipo Missouri, tendo encontrado minério nas localidades de Passo dos Negros e Passo das Canoas23.

Considerando, porém, que os recursos postos à disposição pelo estado seriam muito exiguos se comparados aos federais e considerando ainda a importância e a urgência de dar continuidade aos serviços de mineração, o governo solicitou à Assembléia outra verba maior destinada às instalações oficiais, para que se procedesse à exploração do carvão.

\section{Referia Borges:}

"A intervenção do Estado nesta indústria é uma necessidade evidente em nosso país, ou se realiza sob a forma indireta da concessão de auxilios e favores especiais, como pratica a União, ou se exerce sob a forma de exploração direta, como preferimos e parece ser hoje a tendência geral'" 24 .

Borges enfatizava, dentro de uma perspectiva otimista, como a que caracterizou seu governo na época da guerra, que - Rio Grande apresentava condições "excepcionalmente favoráveis" para a exploração do carvão, não só pela situação das minas como pela "facilidade dos transportes". Cabe aqui lembrar a verdadeira campanha desencadeada pelo governo gaúcho junto ao Congresso Nacional na intenção de transferir para a esfera estadual as obras e serviços da barra e porto do Rio Grande e da Viação Férrea, ambas sob regime de concessionária estrangeira. Borges vinculava, desta forma, a questão energética do estado à solução do problema dos transportes, ou seja: para que o carvão pudesse ser explorado, era preciso que o seu escoamento fácil e barato fosse garantido; para que a questão fosse solucionada com brevidade, era preciso que se demonstrasse a pujança da produção rio-grandense e a necessidade do seu escoamento.

Argumentava ainda o governo que, administrando diretamente, poderia reduzir os gastos de instalações e custeio e aumentar os lucros, além de assumir o papel regulador dos preços do carvão, evitando as especulações demasiadas mas mantendo uma "salutar concorrência com a indústria privada".

O maior benefício advinha, contudo, do fato da intervenção oficial poder, desta forma, coibir a ação dos trustes e mono- 
pólios. Esta era, aliás, uma das preocupações do governo positivista gaúcho. Tanto no caso do carvão quanto no dos frigoríficos, o governo estadual pretendeu, através da intervenção do Estado, eliminar o risco dos monopólios. A mesma argumentação era utilizada no caso dos transportes, com o agravante de que estes se achavam sob controle de empresas estrangeiras que operavam no Rio Grande sem realizar bons serviços para o escoamento da produção. No caso dos frigorificos, ante a entrada de capitais estrangeiros norte-americanos na indústria da carne - Swift e Armour - formara-se uma empresa com capitais locais na qual o Estado tinha participação.

Quanto ao carvão, o governo do estado passou a realizar pesquisas e sondagens na bacia do Gravatai, através da "Divisão dos Serviços Geológicos e Mineralógicos" da Secretaria de Obras Públicas, descobrindo um banco de carvão na área. O objetivo era que a Intendência de Porto Alegre passasse a consumir o carvão de Gravataí e se fizesse a destilação da hulha para iluminação a gás. Por sua vez, quando a produção excedesse ao consumo da Intendência, o carvão seria utilizado nas embarcações da Diretoria da Viação Fluvial e naquelas utilizadas na dragagem dos canais interiores. Numa perspectiva eufórica, pensava-se em, futuramente, utilizá-lo para a produção de energia elétrica para Porto Alegre25.

$\mathrm{Na}$ realização de todas estas atividades de exploração carbonífera e sondagens geológicas, o governo realizou despesas contabilizadas como "especiais" no orçamento do Estado:

"aquisição de maquinaria completa para lavra do carvão

$600: 000 \$$

abertura e revestimento de um poço de grano 150:000\$

despesas com pessoal para lavra e tráfego da mina 200:000\$

despesas com pessoal e material para três sondas rotativas $\ldots \ldots \ldots \ldots \ldots \ldots \ldots \ldots$.

100:000\$

eventuais $(20 \%)$

$210: 000 \$ " 26$

As companhias particulares que operavam no estado (Cia. Estrada de Ferro e Minas de São Jerônimo, em Arroio dos Ratos, e Cia. Carbonífera Rio-grandense, em Minas do Butiá $e$ do Leão) estavam aumentando progressivamente sua produção, 
mas permaneciam problemas decorrentes da falta de seleção e lavagem e melhor aproveitamento como combustivel.

Interessado na economia de divisas, o governo federal desencadeou uma verdadeira campanha pelo uso e consumo do carvão nacional. Precisava suprir de combustivel as estradas de ferro da União e a frota do Lloyd Brasileiro, então já incorporada ao patrimônio nacional.

Neste sentido, o presidente Wenceslau Brás procurou realizar experiências com o carvão gaúcho nos navios do Lloyd e na Estrada de Ferro Central do Brasil, assim como fez remeter amostras para os Estados Unidos, com o fim de se realizarem estudos quanto ao seu uso em pó nas locomtivas27.

Para que isto se efetivasse, contudo, era necessário que se aplicasse um aparelho nas locomotivas, o que permitiria o aproveitamento de um produto de mais baixa qualidade. Quanto a este problema, referia a revista "O Progresso", especializada em assuntos econômicos, em março de 1916:

"Com o uso, dentro de dois anos estariam cobertas as despesas feitas com a montagem dos aparelhos de pulverização e a importância da locomotiva adquirida. É esse um problema para cuja solução seria necessária uma ação conjunta do governo e dos proprietários das minas: o governo facilitando com largueza os meios de transporte com que lutam as minas nacionais e os mineiros aliando a esse interesse oficial os seus esforços, os seus trabalhos, com afinco e perseverança, na exploração de tamanha riqueza" 28 .

Como se vê, mesmo num momento em que se configurava uma conjuntura ótima de mercado, em que as condições de demanda se mostravam favoráveis ao consumo do produto nacional, a qualidade inferior do produto rio-grandense se mantinha como problema, restringindo o seu uso.

Recomendava-se aos industriais de Porto Alegre que procurassem preferentemente a utilização de motores de combustão interna, para os quais o carvão nacional forneceria os gases em condições de bom rendimento, enquanto o carvão inglês continuaria a ser usado preferencialmente nas máquinas a vapor. Neste caso, o carvão sulino não se prestava aos trabaIhos metalúrgicos, não podendo também concorrer com o estrangeiro para "combustivel das fornalhas fixas ou das locomotivas dos dois maiores centros industriais do Brasil, Rio o São Paulo"29. 
O Brasil, no caso, por falta de recursos técnicos e capitais, encontrava dificuldades em realizar experiências com $J$ gasogênio, o motor de explosão e a queima do carvão pulverizado, processos que já se davam na Europa e nos Estados Unidos.

Para proporcionar um melhor aproveitamento de combustível, a Cia. União Fabril, de Rio Grande, havia adaptado em suas fornalhas um pulverizador americano ("The Acre Pulveriser"). Através deste recurso tecnológico, foi possível obter para o quilo do carvão nacional o mesmo rendimento do carvão Cardiff sobre grelhas. O rendimento do carvão gaúcho nas grelhas era de $30 \%$, com perda de $70 \%$ nas calorias produzidas pela combustão. O pulverizador permitira inverter a situação, oportunizando um rendimento de $70 \%$. A máquina importada custara 200 contos e tinha condições de ser adaptada em vapores e máquinas fixas e não nas locomtivas da Viaçâo Férrea30.

Cabe, contudo, lembrar que a União Fabril era das maiores empresas do estado, e este recurso tecnológico não era generalizado em todas as usinas, empresas e companhias do estado, permanecendo o problema de um rendimento não satisfatório do produto nacional em termos de combustão.

Com relação à produção de gás, têm-se referências que, na época da guerra, "fornecedores nacionais, com um carvão de escolha, misturado na razão de $1 / 3$ estrangeiro para $2 / 3$ nacional, com uma técnica especial de carga nas retortas, que consistia em reduzir a quantidade e elevar a temperatura de fusão, conseguiram produzir gás com obtenção do coque aproveitável. O gás resultante era rico em enxofre, exigindo melhor lavagem e purificação" 31 .

As notícias, contudo, são imprecisas, não se sabendo que empresários ou companhias foram estas. Entretanto, sabe-se que o surto carbonifero estadual da época da guerra chegou a ser aproveitado nas grelhas mecânicas das fornalhas de caldeiras inglesas, onde era misturado ao Cardiff. Possuidores de técnica mais sofisticada, os paises europeus tinha melhores condições que o Brasil de obter maior rendimento do artigo nacional.

De qualquer forma, o desenvolvimento da indústria carbonifera propiciou um aumento de um setor específico do proletariado rio-grandense: os mineiros, empregados em grande quantidade em cada uma das companhias que operavam. 
Se, por um lado, representou uma alternativa de trabalho para uma região com poucas possibilidades de emprego de mão-de-obra, por outro, os movimentos grevistas levados a efeito pelos mineiros no decorrer da República Velha serviu para atestar as reais condições de trabalho existentes nas minas.

Pela análise dos motivos que levaram os operários a entrarem em greve, é possivel avaliar a situação dos mineiros frente ao capital:

- demissão de um mineiro acusado de provocar acidente, exigência de demissão de um capataz e necessidade de abertura de um poço de ventilação na mina (greve de 3 a 11 de fevereiro de 1916, São Jerônimo);

- aumento de salário por tonelada de carvão extraído, permissão para sair do interior da mina quando não houvesse trabalho e nomeação de um fiscal pelos mineiros para controie do peso do carvão (greve de 14 a 21 de junho de 1918, Arroio dos Ratos);

- atraso no pagamento dos vencimentos (greves de 8 de janeiro e 5 de setembro de 1920 e 9 de fevereiro de 1923, em Minas do Leão);

- dispensa de mais de 200 operários (greve de 5 de janeiro de 1922, Arroio dos Ratos);

- adulteração no peso do carvão (greve de 15 a 17 de março de 1923, Arroio dos Ratos) ${ }^{32}$.

Como se pode constatar, um dos motivos básicos de reclamação era dado pela necessidade de obter melhores condições de trabalho, tanto no que diz respeito à questão de higene e salubridade dos locais como a própria segurança dos trabalhadores. Inexistindo uma legislação social quanto aos acidentes de trabalho, uma das formas possiveis do capital ver-se livre do trabalhador que se lesionasse em serviço era alegar que o acidente fora provocado. Por outro lado, dando-s? o trabalho em regiões subterrâneas, a falta de luz e ar deveria não apenas provocar acidentes como possibilitar a proliferação de doenças pulmonares e de visão.

Outra questão que aparece com realce é o da venalidade da fiscalização da tonelagem do carvão por parte dos agentes 
da companhia, lesando com isso os mineiros nos seus salários. Aliás, a questão salarial também se apresentava como uma das mais invocadas, solicitando-se não apenas aumento de vencimentos mas o recebimento do pagamento em dia. Em determinados casos, os atrasos davam-se na ordem de cinco meses (greve de 5 de novembro de 1920) ou mesmo 10 meses greve de 9 de fevereiro de 1913)!

Finalmente, cabe ainda apontar a inexistência de garantias quanto à permanência do indivíduo no emprego.

As duras condições de trabalho nas minas deveriam ser severamente fiscalizadas, pelo que aparece a reivindicação de remoção de um capataz entre os motivos que deflagaram greves.

Embora alguns movimentos tenham obtido sucesso quanto às suas pretensões, como o ocorrido em Arroio dos Ratos, entre 14 e 21 de junho de 1918, envolvendo 400 mineiros da Cia. de Estradas de Ferro e Minas de Carvão de São Jerônimo, na maioria dos casos a repressão se fez sentir duramente, tendo as autoridades assegurado ao capital as condições de sujeição do trabalho. Ora a delegacia de polícia da área entrava em cena a pedido dos diretores de companhia mineira ameaçada, ora as próprias famílias dos mineiros sofriam violência por parte dos policiais (caso da greve de 15 a 17 de março de 1923, em Arroio dos Ratos).

É interessante e merecedor de registro o incidente ocorrido em São Jerônimo, em fevereiro de 1921, quando um advogado foi preso pelo subintendente do distrito, sob o pretexto de aconselhar greve aos operários. Ouvido o acusado, este alegou tratar-se de uma vingança da companhia contra a sua pessoa, uma vez que, no exercício de sua profissão, havia movido ações contra a empresa por acidente no trabalho... ${ }^{33}$

Terminado o conflito, o combustível estrangeiro voltou a fazer concorrência ao nacional, na medida que se restabeleceu a normalidade dos transportes.

O início da década de 20 foi marcado pelo esgotamento do tipo de desenvolvimento capitalista em curso no país até então. O padrão de acumulação baseado na agroexportação cafeeira entrava em declínio, na proporção que a intermediação comercial-financeira externa passou a consumir parte do excedente econômico produzido. 
Acentuaram-se as ligações com o capital, enraizando-se mais a dependência.

Em 1920, anunciava-se que o governo federal dera uma concessão à Itabira Iron Ore Company, organizada pelo capitalista Percival Farquhar, mediante a qual a companhia norteamericana obtinha favores para a exportação de minério de ferro e importação de carvão de pedra34.

Embora a fração dirigente da burguesia agrária fosse levada a firmar estes acordos em função de seus compromissos com o capital estrangeiro, necessário para a sustentação de seu produto básico, esta situação não era bem vista no seio de toda a classe dominante nacional.

Por exemplo, no Rio Grande do Sul a encampação da Viação Férrea pelo governo do estado, em 1920, fez com que retornasse o interesse pelo emprego do carvão nacional.

Além das companhias particulares que operavam no estado, o governo rio-grandense tinha sua atenção voltada para o carvão do Gravatai, explorado pelo estado, que começava a fornecer combustivel para a Viação Férrea. Neste caso, o governo abriu concorrência entre casas inglesas e americanas e aceitou a proposta da firma Head, Wrighton \& Co. para operar no beneficiamento do carvão extraido35.

Nos serviços das minas de Gravataí, o governo, que a princípio recrutara trabalhadores remunerados por dia de trabalho de oito horas, passou a seguir a contratar os operários por empreitada, por considerar ser "mais conveniente". Através de tal medida, a intenção do governo estadual era intensificar a jornada de trabalho e a produtividade, obtendo maior produção em menos tempo.

Paralelamente, continuaram experiências para a melhor utilização do combustível, procurando adaptar a sua queima em todas as fornalhas das locomotivas em serviço na Viação Férrea e melhorar a qualidade do carvão gaúcho pela lavagem.

Quanto a este último aspecto, em 1922 foram inauguradas, em São Jerônimo, instalações para a lavagem do carvão.

Conjugando a "solução do caso dos transportes" com a "questão energética", o objetivo final do governo estadual era 
aumentar a produção e baixar o seu custo, permitindo a sua competição com o artigo estrangeiro.

Entretanto, todas estas ações conjugadas - abertura de novos poços, prospecção, extração, lavagem, experimentações, aquisição de máquinas e desenvolvimento dos transportes exigiam um volume de capital que a conjuntura depressiva do pós-guerra em nada facilitava.

O Rio Grande, no caso, atravessava uma fase dificil, na medida que seu principal produto de exportação, o charque, se encontrava em crise.

Em suma, o custo da produção do carvão mantinha-se elevado.

Em 1923, foram suspensas as obras de instalação e abertura de poços nas minas de Gravataí e de construção de uma linha férrea para o transporte do produto até o porto das $\mathrm{Ca}$ noas, no rio Gravatai. Em 1924, os serviços foram paralisados de todo, e o governo abriu concorrência pública para o arrendamento da mina 36 . A única companhia que apresentou proposta e que foi aceita pelo governo rescindiu o contrato de sublocação da mina em janeiro de 1926, ficando a mesma sob a supervisão da Diretoria do Serviço Geológico e Mineralógico do Estado37. Esse restringiu-se apenas aos trabalhos de conservação da mina, até que, em 1928, a mesma passou à guarda da Companhia de Estradas de Ferro e Minas de São Jerônimo 38 .

Permaneciam operando no estado esta companhia e mais a Carbonifera Rio-grandense, com as quais o governo firmara contrato a fim de que fornecessem combustivel para a Viação Férrea.

As novas locomotivas, importadas pelo estado a partir de 1921, já vieram devidamente aparelhadas para a utilização do carvão nacional.

Em 1928, a Cia. Estrada de Ferro e Minas de São Jerônimo fornecia mensalmente 10000 toneladas e anualmente $120000 \mathrm{t}$. A produção da Cia. atingiu neste ano 250610t. A Cia. Carbonifera Rio-Grandense, por seu lado, entregava à Viação Férrea 3500 t. mensais e 42000 por ano. O contrato com a Cia. de São Jerônimo determinava ainda a construção de uma ponte sobre o rio Jacui, destinada a facilitar o transporte do carvão. 39 
O próprio aumento da demanda interna pelo carvão nacional, portanto, incentivou a expansão da produção das duas companhias que operavam no estado.

\section{2 - A REPÚBlicA NOVA E A QUESTÃO ENERGÉTICA}

A crise econômica que acompanhou a transição da República Velha para a Segunda República também afetou a indústria carbonifera do estado.

$\mathrm{Na}$ realidade, o periodo pós-30 assistiria a uma reformulação da economia brasileira. Face a crise do setor cafeeiro, até então núcleo dinâmico da acumulação no país, o governo revolucionário teve como problema principal a busca de saídas para o desenvolvimento capitalista brasileiro.

Ao longo dos anos 30 , foram realizadas inúmeras tentativas para a diversificação da economia nacional, estimulando a expansão de novos produtos e amparando diferentes atividades das diversas regiões do país.

Outras medidas complementares levadas a efeito pelo governo foram a busca da integração do mercado interno, o aumento das exportações e a diminuição das importações. Como forma de conseguir esta reorientação global da economia brasileira, processou-se uma crescente intervenção do Estado nos mais diferentes setores.

Dentro deste quadro geral, acentuaram-se as relações de dependência entre o Rio Grande do Sul e o centro, caracterizando-se o estado sulino como fornecedor de gêneros alimentícios a baixo preço e de outros insumos para fomentar o crescimento da economia nacional.

É nesta conjuntura especifica, de crise econômica mundial e rearticulação interna, que ganhou força a questão energética.

O retraimento do comércio internacional e a perturbação das economias capitalistas afetadas pela crise de 29 , bem como os efeitos da mesma sobre a economia brasileira, estavam tornando cada vez mais dificil e onerosa a importação do carvão estrangeiro. Neste ponto, o carvão do sul do país apresentava-se como o substitutivo ideal do Cardiff. Impulsionada a sua extração e comercialização para o restante do pais, propiciava-se tanto a diversificação da economia nacional quanto a integração do mercado interno, além de se economizarem divisas com a diminuição das importações. 


\section{PRODUÇÃO GAÚCHA DE CARVÃO NO QÜINQUEENNIO 1932/1936, COMPARATIVAMENTE COM A MÉDIA QUINQÜENAL DE 1927/1931}

Pelos dados acima expostos 40 , pode-se observar o cresc:mento da produção carbonifera estadual no decorrer da República Nova, estimulado pela conjuntura econômica do momento e pela ação dos governos federal e estadual.

Como o produto possuia pouco poder calórico, era necessário que fosse amparado por uma política protecionista quanto aos direitos aduaneiros frente ao carvão inglês.

Procurando favorecer a produção nacional do minério, Getúlio Vargas assinou o Decreto n०20.089, de 9 de junho de 1931, tornando obrigatório, para os importadores de carvão estrangeiro, a aquisição de $10 \%$ de carvão nacional 41 .

Paralelamente, foram elevadas as tarifas alfandegárias sobre o produto estrangeiro.

Tais medidas criaram condiçöes para $\circ$ alargamento do consumo do carvão nacional, bem como propiciaram a venda do produto para fora do estado. Neste pondo, coadunavam-se os interesses dos governos federal e estadual. O primeiro, por encontrar na expansão da produção carbonífera rio-grandense a materialização de suas metas governamentais; o segundo, porque era preocupação do estado e dos produtores conquistar o mercado nacional.

Fazendo um confronto, no ano de 1936, entre a exportação de cabotagem do carvão gaúcho com a importação do exterior e de cabotagem do mesmo produto, vê-se que a produção local representava mais que o dobro da importação42:

A situação, no caso, invertera-se, se for considerado que, no início do século, o carvão local representava a metade do carvão estrangeiro consumido no estado.

Dentro do Rio Grande, o combustível era usado pelos estabelecimentos fabris de Porto Alegre, Pelotas e Rio Grande, mas seu destino básico era a Viação Férrea43. Visando ao aproveitamento do carvão gaúcho, a Companhia de Energia Elétrica Rio-grandense procedeu a realização de experiências nos Estados Unidos com o fim de instalar em Porto Alegre uma usina. Em 1932, achava-se em andamento a sua instalação, 
na qual se objetivava produzir betume, benzol (combustivel para motores), carrapaticidas (até então importados) e gás para domicilios na capital44.

Também aproveitavam o carvão gaúcho as usinas de $\mathrm{Pe}$ lotas e Rio Grande.

No tocante à exportação do produto para fora do estado, de uma produção de $74.892 t$ no primeiro semestre de 1933, o Rio Grande do Sul enviava para fora 24.338t. Captava, com isso, os interesses das empresas consumidoras de carvão no pais: a companhia The Great Western, de Recife, a São Paulo Rallway e as Indústrias Reunidas Matarazzo, de São Paulo45.

A Cia. Carbonifera Rio-grandense, por seu lado, empenhava-se para que o carvão gaúcho passasse a ser usado em estabelecimentos fabris do Rio de Janeiro 46.

No prosseguimento desta expansão, em 1935 era remetida, a título de experiência, uma partida de carvão rio-grandense para a Itália.

Segundo declarações do diretor da Cia. Carbonífera Riograndense, esta companhia mais a Cia. Estradas de Ferro e Minas de São Jerônimo estavam produzindo de forma a que só $8 \%$ do carvão consumido no estado fosse estrangeiro 47 .

Quanto ao governo estadual, este procurou beneficiar a indústria carbonifera gaúcha, isentando-a do pagamento dos impostos estaduais e municipais.

Pelo Decreto no 4.699, de 17 de janeiro de 1931, as empresas exploradoras do carvão mineral do estado foram favorecidas com a isenção por dois anos de todos os impostos e das taxas portuárias quando efetuassem suas operações de carga e descarga fora do cais em tráfego, sem utilização de aparelhos e serviços dos portos. Tais favores foram renovados em 193348 .

Em 1935, em função de petição apresentada à Assembléia pela Cia. Estradas de Ferro e Minas de São Jerônimo e Cia. Carbonífera Rio-grandense, estes favores foram concedidos por mais dois anos 49 .

O governo de Flores da Cunha tinha interesse no emprego do carvão gaúcho não apenas na Viação Férrea, mas também 
na projetada Frota Rio-grandense. Embora Vargas pretendesse reerguer a marinha mercante nacional com o Lloyd Brasileiro, Flores pretendia criar uma companhia estadual de navegação com o objetivo de diminuir os fretes, favorecendo o escoamento da produção gaúcha50.

Com relação à questão energética, as preocupações dos governos federal e estadual não se limitaram à questão do carvão no decorrer da República Nova. Em 1931, Getúlio Vargas assinou um decreto obrigando a mistura de álcool-motor a toda gasolina importada. Tal medida visava a diminuir a importação da gasolina, num periodo em que se tentava coibir a evasão de divisas. Ao mesmo tempo, obtinha-se uma forma de diversificação econômica, com o desenvolvimento da lavoura da cana-de-açúcar 51 . O governo federal ainda concedia liberdade para importar, sem direitos aduaneiros, aparelhos para destilação do álcool.

Em função de tais estimulos, formou-se no Rio Grande do Sul, em 1931, a Sociedade do Álcool Motor Ltda., sob a liderança de Pedro Licht, comerciante de Porto Alegre, e Antônio José Tedesco, industrial de Viamão, com o objetivo de atender aos fins previstos pelo decreto do governo federal. $\mathrm{Na}$ fazenda do Paquete, município de Caí, Nicolau Kroeff fabricava álcoolmotor, principalmente de mandioca, que lá era cultivada em larga escala52. Da mesma forma, Bernardo Droher, proprietário de uma usina em Conceição do Arroio, produzia álcoolmotor, tendo solicitado e obtido de Flores da Cunha, em 1931, isenção de todos os impostos sobre este produto53.

Em suma, a questão energética preocupava os poderes públicos nestes anos que se seguiram à crise mundial de 29 , acarretando alterações no comércio internacional, tornando mais caras as importações e obrigando os paises a um esforço substitutivo. Dai, pois, os estímulos criados às fontes internas alternativas de energia existentes no país.

Apesar de uma situação aparentemente auspiciosa para a produção do carvão rio-grandense, os produtores do estado recorreriam mais uma vez à Assembléia Legislativa, em 1936. Alegavam que o Decreto n? 20.089, de Vargas, fixava a quota do carvão a ser adquirido pelos importadores, mas não o preço do mesmo, gerando sérias controvérsias entre os produtores e as grandes companhias.

Segundo os produtores de carvão, o frete do Rio Grande ao Rio de Janeiro ou Santos era maior do que o de Hamburgo 
ou Liverpool ao Rio de Janeiro, devido às altas subvenções que recebiam os navios estrangeiros que transportavam carvão. Tal subvenção anulava a tarifa alfandegária que protegia as minas do pais.

Fora firmado um convênio entre todas as companhias de navegação de cabotagem que estabeleciam um alto frete. preço do produto, contudo, não podia ser muito alto, tanto devido à qualidade do carvão como pelo fato do governo federal não querer que o consumidor fosse atingido.

Além de todos estes problemas que prejudicavam os produtores de carvão, os empresários alegavam que os encargos sociais com a legislação trabalhista estavam fazendo diminuir os lucros 54 .

Em face de todo este arrazoado, os representantes da $\mathrm{Cia}$. Carbonífera Rio-grandense e da Estradas de Ferro e Minas de São Jerônimo solicitavam que se mantivesse por quatro anos a concessão especial feita por ocasião do contrato com a Estrada de Ferro Central do Brasil em 1933. Através desta cláusula, concedia-se isenção de impostos para o carvão, inclusive as taxas relativas à carga e descarga. Pelo contrato de fornecimento, as taxas portuárias seriam pagas pela Estrada de Ferro. A Cia, por seu lado, obrigava-se a fornecer 100000 toneladas anuais. O pedido obteve aprovação da Assembléia.

Segundo a argumentação apresentada, alguns pontos merecem discussão.

Primeiramente, a permanência do alto custo dos transportes no Rio Grande do Sul, mesmo depois da encampação do porto, em 1919, e da Viação Férrea, em 1920, ambas pelo governo federal. Outro aspecto a ser destacado é o fato da qualidade do carvão, conforme o interesse do momento, ser invocada como boa ou má.

Cabe lembrar também a questão do preço do produto. Os interesses do governo federal, no caso, eram de que o Rio Grande fornecesse insumos para a expansão da produção nacional, não querendo repassar os custos de uma produção onerosa para o preço de venda ao industrial que utilizava o censo como insumo. Desta forma, era possivel conciliar uma política inflacionária e de expansão econômica com o pagamento de baixos salários ao trabalhador nacional. 
Ainda com relação a esta questão do trabalhador, cabe assinalar a posição desta parcela da burguesia gaúcha - os proprietários das minas - que, assim como toda a classe, relutaram em compreender o verdadeiro sentido da legislação social, que fora feita basicamente para proporcionar a acumulação de capital e anular o potencial político do operário. O operário, por seu turno, foi parte dele "neutralizado" no início d'os anos 30 pela aplicação da legislação social. É bem verdade que, a partir de 1935, recrudesceram o movimento operário, as greves e a ação do Partido Comunista, e surgiu a Aliança Nacional Libertadora, de efêmera duração, mas parte do operariado foi seduzida pelas leis trabalhistas.

Em 1931, por ocasião da vinda do Ministro do Trabalho Lindolfo Collor a Porto Alegre, o mesmo visitou a Cia. Estradas de Ferro e Minas de São Jerônimo. A companhia empregava 1.658 operários, sendo 1.406 brasileiros e 252 estrangeiros. Foram enfatizadas pelos jornais da época as condições de segurança e salubridade do trabalho dos mineiros, que contavam também com atividades recreativas e de assistência.

\section{Referia o Correio do Povo:}

"Falando a um dos mais antigos operários, o ministro indagou há quantos anos estava ele a serviço da companhia. Respondeu que tinha 59 anos e que trabalharia até quando as forças o permitissem, não desejando aposentadoria. 55

Outro operário discursou, louvando os esforços do governo provisório em conciliar os interesses de patrões e empregados.

Seguramente, esses elementos eram "escolhidos a dedo" para realizarem tais saudaçōes durante uma visita oficial.

Em 1933, as instalações da Cia. Estrada de Ferro e Minas de São Jerônimo foram visitadas pelo Dr. Ernani de Oliveira, Inspetor Regional do Trabalho no estado e pelo Dr. Valdir Niemeyer, enviado especial do Ministério do Trabalho. Entrevistado pelo Correio do Povo, o Dr. Niemeyer se declarou impressionado com os serviços das minas. Tendo descido num dos poços e percorrido várias galerias, constatou a sua "boa ventilação." Por ocasião da visita, aproveitara para instalar o Sindicato dos Mineiros, dando posse a uma diretoria provisória que deveria tratar do reconhecimento da nova entidade junto ao Ministério do Trabalho. A diretoria da Cia. de São Jerônimo prestigiara este ato. 
Finalizando a entrevista, o Dr. Niemeyer declarou:

"Trouxe de todos os trabalhos realizados uma impressão boa do espírito de camaradagem entre operários e altos dirigentes daquela companhia, que cedeu um lugar especial para as reuniões provisórias. $\mathrm{O}$ ambiente encontrado aqui é de plena confiança entre as duas partes, sendo que na Cia. Estrada de Ferro e Minas de São Jerônimo vi os trabalhos de construção de casas para operários, estando estes satisfeitos pela forma como são tratados." 56

O discurso da classe dominante, no caso, se mostra particularmente rico em análise, pondo inclusive a algumas das formas pelas quais se conduzia o processo de dominação do capital sobre o trabalho. A implantação da legislação social e da sindicalização obrigatória buscava não apenas anular o potencial político do operário como possibilitar a acumulação. Note-se, no caso, a ênfase na colaboração entre empregados e empregadores, o destaque para a atitude paternalista da empresa com relação aos trabalhadores e a própria instalação de um sindicato tutelado pelo Estado.

Tais exemplos de encaminhamento do problema social, evidentemente, não abrangem toda a dinamicidade e a riqueza das condições históricas da existência real do trabalho nas minas.

Todavia, servem em parte para exemplificar que, se por um lado uma parcela do proletariado tendia a creditar no governo em face da legislação trabalhista, por outro lado, parcela da burguesia oscilava entre o medo da perda de lucros com os encargos sociais e o reconhecimento de que a sindicalização tutelada pelo governo era um instrumento eficaz no controle do operariado.

Em síntese, é possivel acompanhar o desenvolvimento da indústria carbonífera no Rio Grande do Sul, vinculada à questão energética do país. Mesclaram-se, nos interesses em jogo, tanto os do capitalismo internacional quanto os dos governos federal e estadual. Todos, basicamente, visavam, através da exploração das minas, fornecer combustivel para um mundo em transformação, marcado pela emergência das indústrias, da máquina a vapor, das usinas geradoras de eletricidade e da expansão das ferrovias.

Inicialmente explorado por capitais ingleses, que ante os obstáculos e dificuldades se retiraram do negócio, a indústria 
carbonifera passou, após, a ser alvo de investimento dos capitais nacionais. Este momento coincidiu com a internalização do capitalismo no Brasil e com a atuação dos governos central e federal no sentido de incentivar a exploração das fontes de energia do pais.

Esta preocupação acentuou-se após a crise de 29 , com suas repercussões sobre as economias periféricas e recolocando, como problema, a questão da energia.

Universidade Federal do Rio Grande do Sul

Departamento de História

Porto Alegre - Brasil

NOTAS

1 CHAVES, Antônio José Gonçalves. Memórias tcônomo-políticas. Porto Alegre, Ers, 1978. p. 123-4.

2 PENZ, Roselena Lisboa. Influência inglesa na economia do Rio Grande do

Sul durante o II Império; 1841-1889. Porto Alegre, UFRGS, 1980. p. 65.

3 PENZ, op. cit.

4 MULHALL, Michael G. O Rio Grande do Sul e suas colônias alemãs.

Porto Alegre, Bells - IEL/DAC/SEC, 1974. p. 73.

5 MULHALL, op. cit.

6 RELATÓRIO do Presidente da Provincia do Rio Grande do Sul. 1881. p. 62.

7 RELATÓRIO do Presidente da Provincia do Rio Grande do Sul. 1888. p. 25.

8 RELATÓRIO do Presidente da Provincia do Rio Grande do Sul. 1888.

9 MENSAGEM do Presidente do Estado do Rio Grande do Sul. 1917. p. 59. 10 MENSAGEM do Presidente do Estado do Rio Grande do Sul. 1902. p. 17. 11 O RIO GRANDE DO SUL Industrial. Porto Alegre, Echenique \& Irmão, 1907. p. 20.

12 O RIO GRANDE..., op. cit.

13 ESPIRITO SANTO, Miguel Frederico do. Implicação da abertura da barra do Rio Grande na realização de um modo dep rodução capitalista no estado; periodo de 1890 a 1920. Porto Alegre, UFRGS, 1978. p. 39-40. 14 MENSAGEM do Presidente do Estado do Rio Grande do Sul. 1900. p. 29. 15 REVISTA PAULISTA de Indústria. Dez. 1955. № 41. Ano V. Economia do Rio Grande do Sul. v. 1. p. 163.

16 MENSAGEM do Presidente do Estado do Rio Grande do Sul. 1904. p. 33. 17 REVISTA PAULISTA..., op. cit., p. 163.

18 MENSAGEM do Presidente do Estado do Rio Grande do Sul. 1915.

19 MENSAGEM do Presidente do Estado do Rio Grande do Sul. 1917. p. 61-2. 20 MENSAGEM do Presidente do Estado do Río Grande lo Sul. 1917. p. 60. 21 MENSAGEM do Presidene do Estado do Rio Grande do Sul. 1918, p. 57. 22 MENSAGEM do Presidente do Estado do Pio Grande do Sul. 1917. p. 66. 23 MENSAGEM do Presidente do Estado do Rio Grande do Sul. 1918, p. 34. 24 MENSAGEM do Presidente do Estado do Rio Grande do Sul. 1917. p. 65. 
25 MENSAGEM do Presidtnte do Estado do Rio Grande do Sul. 1919. p. 45-6. 26 MENSAGEM do Presidente do Estado do Rio Grande do Sul. 1919. p. 22. 27 REVISTA DO COMÉRCIO e Indústria de São Paulo. Set. 1919. Ano V. N : 57. p. 287-8.

28 MENSAGEM do Presidente do Estado do Rio Grande do Sul. 1919. p. 47-8. 29 O PROGRESSO. Abr. 1916. Ano IV. № 31.

30 MENSAGEM do Presidente do Estado do Rio Grande do Sul. 1919. p. 48.

31 REVISTA PAULISTA..., op. cit., p. 163-4.

32 PETERSEN Silvia Regina Ferraz. As greves no Pio Grande do Sul (18901919). In: DACANAL J. H. \& GONZAGA, S. (org.) RS: economia e politica. Porto Alegre, Mercado Aberto, 1979. p. 294 e 297.

33 CORREIO do Povo. Porto Alegre, 20 fev. 1921. p. 7.

34 REVISTA DO COMÉRCIO e Indústria de São Paulo. São Paulo, 1920. p. 206-7.

35 MENSAGEM do Presidente do Estado do Rio Grande do Sul. 1921. p. 93. 36 MENSAGEM do Presidente do Estado do Rio Grande do Sul. 1924. p. 28. 37 MENSAGEM do Presidente do Estado do Rio Grande do Sul. 1916. p. 36. 38 MENSAGEM do Presidente do Estado do Rio Grande do Sul. 1929. p. 74. 39 MENSAGEM do Presidente do Estado do Rio Grande do Sul. 1929. p. 66. 40 ANUARIO ESTATISTICO do Estado do Rio Grande do Sul. 1940. p. 78. 41 ANAIS da Assembléia Legislativa do Estado do Rio Grande do Sul. 1936.

Sessão de 8 ago. 1936. $53^{\circ}$ sessão. v. 2.

42 ANUARIO ESTATISTICO..., op. cit., p. 116, 120, 122.

43 CORREIO do Povo. Porto Alegre, 22 jan. 1931. p. 7.

44 CORREIO do Povo. Porto Alegre, 25 fev. 1932. p. 16.

45 CORREIO do Povo. Porto Alegre, 13 jul. 1933. p. 3.

46 CORRE!O do Povo. Porto Alegre, 10 mar. 1931. p. 5.

47 CORREIO do Povo. Porto Alegre, 9nov. 1935. p. 9.

48 MENSAGEM do Pres'dente do Estado do Pio Grande do Sul. 1935. p. 92. 49 ANAIS da Assembléia Legislativa do Estado do Rio Grande do Sul. 1935.

Sessão de 4 nov. 1935. $90^{\circ}$ sessão. Porto Alegre, Imprensa Oficial, 1936. v. 2.

50 CORREIO do Povo. Porto Alegre, 27 out. 1935. p. 11.

51 CORREIO do Povo. Porto Alegre, 3 mar. 1931. p. 7.

52 CORREIO do Povo. Porto Alegre, 12 jun. 1981. (Suplemento Rural)

53 CORREIO do Povo. Porto Alegre, 17 fev, 1931. p. 7.

54 ANAIS da Assembléia Legislat'va do Estado do Rio Grande do Sul, 1936.

Sessão de 8 ago. 1936. $53^{\text {ạ }}$ sessão. v. 2.

55 CORREIO do Povo. Porto Alegre, 1ং dez. 1931.

56 CORREIO do Povo. Porto Alegre, 16 fev. 1933. p. 8. 